\title{
Creating a More Accessible Environment for Our Users with Disabilities: Responding to an Office for Civil Rights Complaint ${ }^{1}$
}

\author{
By Donna E. McCrea
}

ABSTRACT: In 2012, a University of Montana student advocacy organization filed a complaint with the US Department of Education's Office for Civil Rights stating that unequal access to the university's electronic and information technologies (EIT) resulted in discrimination against students with disabilities. This article shares ways in which the University of Montana, including its archives and special collections, responded to the resulting mandate that "employees must create, obtain, and maintain all EIT in a manner that ensures it is accessible to individuals with disabilities." The author argues that a professional and ethical commitment to diversity, access, and use compels archivists and colleagues in the cultural heritage community to increase their awareness of accessibility issues as they relate to electronic and information technologies, and to act to eliminate barriers experienced by their users with disabilities.

\section{Introduction}

In May 2012, the student organization Alliance for Disability and Students at the University of Montana filed a complaint with the US Department of Education's Office for Civil Rights (OCR) alleging that unequal access to the University of Montana's electronic and information technologies resulted in discrimination against students with disabilities. The University of Montana (UM) was not the first institution of higher education to face potential legal action related to inaccessible technology, but it was one of the first to have its library specifically named in an OCR complaint. ${ }^{2}$ The complaint cited

inaccessible class assignments and materials on the learning management system, Moodle; inaccessible live chat and discussion board functions in the learning management system, Moodle; inaccessible documents that are scanned images on webpages and web sites; inaccessible videos, and videos in Flash format, that are not captioned; inaccessible library database materials; inaccessible course registration through a web site, Cyber Bear; and inaccessible classroom clickers. ${ }^{3}$

A Resolution Agreement, voluntarily entered into by the OCR and UM in March 2014, outlined remedial actions to be taken by UM. These included appointing an electronic and information technology (EIT) coordinator for the campus, conducting a campuswide EIT Accessibility Audit, developing an EIT Corrective Action Strategy, and creating a formal grievance procedure. Also mandated was the development of an 
Electronic and Information Technology Accessibility (EITA) Policy and Procedure, ${ }^{4}$ which requires that "UM employees must create, obtain, and maintain all EIT in a manner that ensures it is accessible to individuals with disabilities." ${ }^{5}$ In the terminology of the UM Resolution Agreement,

"Accessible" means that individuals with disabilities are able to independently acquire the same information, engage in the same interactions, and enjoy the same services within the same timeframe as individuals without disabilities, with substantially equivalent ease of use. ${ }^{6}$

UM has made - and continues to make-changes in its electronic and information technology to create a more accessible and inclusive environment for individuals with disabilities. This article shares ways in which the University of Montana's Maureen and Mike Mansfield Library, and its Archives and Special Collections, responded to the Resolution Agreement and to UM's EITA policy and procedures. The author's first goal is to raise awareness about EIT issues as they relate to access and use of archives and special collections. A second goal is to encourage archivists and others in the cultural heritage community to select and create technology, resources, and services with a conscious commitment to eliminating barriers for our users with disabilities.

\section{Legislative Review}

The University of Montana-Missoula, the flagship campus of the Montana University System, is a public research university serving approximately 12,000 undergraduate and graduate students. As a public institution, it receives financial assistance from the US Department of Education. Several civil rights laws prohibit discrimination in agencies and in programs or activities that receive federal funding. The Americans with Disabilities Act (ADA), adopted in 1990 and amended in 2008, states that "No qualified individual with a disability shall, on the basis of disability, be excluded from participation in, or be denied the benefits of the services, programs or activities of a place of public accommodation." 7 Title II of the ADA applies to public entities, including local and state governments. Section 504 of the Rehabilitation Act of 1973 provides that "No otherwise qualified individual with a disability in the United States . . . shall, solely by reason of her or his disability, be excluded from the participation in, be denied the benefits of, or be subjected to discrimination under any program or activity receiving Federal financial assistance." ${ }^{8}$ Section 508 of the Rehabilitation Act, as amended in 1998, "applies to all Federal agencies when they develop, procure, maintain, or use electronic and information technology. Under Section 508, agencies must give disabled employees and members of the public access to information that is comparable to access available to others." 9

The OCR and the US Department of Justice (DOJ) each enforce compliance with portions of the ADA and the Rehabilitation Act on academic campuses. A joint Dear Colleague Letter, authored in June 2010 by the OCR and the DOJ, explains that "federal 
law prohibits colleges and universities from using . . . any emerging technology without insisting that such technology be accessible to all students." ${ }^{10}$ A number of states, including Montana, have also adopted some form of accessible information technology laws, and most states have policies or standards addressing accessible websites. ${ }^{11}$ In other words, there are legal reasons why many archivists should proactively consider accessibility in the design and delivery of products and services.

\section{Accessibility and Professional Ethics}

There are, of course, reasons besides the law to create and select products and services that enable participation by the broadest number of individuals. According to a 2012 report by the US Census Bureau, more than one in five people in the United States have a disability; at over 19 percent, people with disabilities make up the largest minority population in the United States. For example, "[a]bout 8.1 million people had difficulty seeing, including 2.0 million who were blind or unable to see. About 7.6 million people experienced difficulty hearing, including 1.1 million whose difficulty was severe." ${ }^{12}$ Physical or cognitive impairments may be present at birth, may be the result of a single incident, such as a stroke or a car accident, or may develop over time, such as impairments related to aging.

The archival profession is committed to making content available to its audiences. The core values of the Society of American Archivists (SAA) include diversity, service, social responsibility, and the value of access and use. Access and use are also addressed in SAA's Code of Ethics which reads, in part,

Recognizing that use is the fundamental reason for keeping archives, archivists actively promote open and equitable access to the records in their care within the context of their institutions' missions and their intended user groups. They minimize restrictions and maximize ease of access. They facilitate the continuing accessibility and intelligibility of archival materials in all formats. ${ }^{13}$

Allied professions, within which many archivists work, also address access to resources in their ethics statements. For example, the American Alliance of Museums states, "Museums serve society by advancing an understanding and appreciation of the natural and cultural common wealth through exhibitions, research, scholarship, publications and educational activities ... [these activities] are accessible and encourage participation of the widest possible audience consistent with its mission and resources." 14 The American Library Association's ethics code asserts, "We provide the highest level of service to all library users through appropriate and usefully organized resources; equitable service policies; [and] equitable access." ${ }^{15}$ The Association of Research Libraries' Code of Best Practices reads, in part, "Research libraries have a responsibility to make library collections and services universally accessible to their patrons. Doing so is consonant with research library community values and is also necessary in order to comply with longstanding legal requirements." 16 


\section{Literature Review}

A handful of archivists have written about accessibility issues as they relate specifically to access to archival materials by people with disabilities. In a 1979 article in The American Archivist, Lance J. Fischer encouraged his colleagues to do a better job of making their resources and information about their services available to the deaf. He also urged archivists to make themselves aware of "information related to the elimination of those obstacles that prevent the handicapped from leading normal, productive lives." ${ }^{17}$ Brenda Beasley Kepley wrote in 1983, "The greatest barriers confronting the disabled are the attitudes and behavior of the able-bodied.... Our first goal should therefore be to educate ourselves and our staffs." ${ }^{18}$ Kepley listed practical steps archivists should take to facilitate access, many of which are still relevant today, and noted, "When making decisions about access to our collections for the disabled, we should keep in mind that anything we do for the disabled will, to a great extent, benefit other researchers, particularly the aging."${ }^{19}$ In the fall 1993 issue of The American Archivist, Ronald L. Gilardi provided an overview of the sections of the 1990 Americans with Disabilities Act that were most likely to impact archives and archivists, including Title I provisions against discrimination in employment, Title II requirements for equal access to the "benefits of the services, programs, or activities of a public entity," and Title III provisions requiring that places of "public accommodation," including a "museum, library, gallery or other place of public display or collection," provide for "equal enjoyment" of the facility and its services. ${ }^{20}$ In 2008, Frank H. Serene of the National Archives and Records Administration outlined ways to make both archives' physical environments and their services accessible to staff and researchers with disabilities. ${ }^{21}$ In 2010, the SAA Council adopted "Best Practices for Working with Archives Researchers with Physical Disabilities." The "Best Practices" document, drafted by SAA's Joint Working Group on Accessibility in Archives and Records Management, makes basic recommendations for the design of buildings, grounds, public programming spaces, and research areas; for communicating with researchers; for making accessible technology available to researchers; and for creating accessible electronic materials. ${ }^{22}$ The Joint Working Group sponsored Accessibility Awareness Forums at SAA in 2010 and 2011, and maintains an Accessibility Working Group website. ${ }^{23}$

Recent articles explore the accessibility of archives' websites and of content placed online by archives and special collections. Lora J. Davis evaluated compliance of the home pages of several archival repository websites with Website Content Accessibility Guidelines (WCAG). ${ }^{24}$ She advised, "If a web presence is deemed to be worth developing, then the same care and attention should be paid to its accessibility as is paid to its visual appeal, content (spelling, grammar and punctuation) and accuracy. ... Many of the changes that are likely to occur on institutional websites as a result of accessibility audits will likely improve the usability of such sites for both users with disabilities and members of the abled public." ${ }^{25}$ Lisa Snider offered a "list of the most important changes you can make to your archives' website to help make it more universally accessible" to people using assistive technologies. ${ }^{26}$ This list includes using appropriate heading tags (which allow assistive technology to identify and move from 
one section of a page to another); providing text descriptions of images (often referred to as alternate text or alt-text); using hyperlink text that is meaningful (a link that reads "contact a staff member" rather than a phrase that reads "to contact a staff member" followed by a link that reads "click here"); and providing text transcripts for audio and video content. ${ }^{27}$ Kristina L. Southwell and Jacquelyn Slater reviewed if and how the main informational content of digitized handwritten and typed textual documents from the collections of 69 Association of Research Libraries' institutions were accessible to individuals using screen readers. They concluded, "The digitized documents that were accompanied by transcripts or could be digitally read (such as OCR [optical character recognition] text) are clearly more accessible to patrons. ${ }^{28}$ However, they also noted that no matter how accessible the document itself is, to be discovered and accessed the software rendering that document must function effectively with screen readers. ${ }^{29}$ Southwell and Slater also evaluated the accessibility of finding aids to people using screen readers and pointed out that many finding aids do not include document language (which is important to text-to-speech applications), form labels, or alt-text for linked images. ${ }^{30}$ Their article offered a list of checkpoints, such as keyboard-friendly navigation and clear navigational structure, which should be incorporated into the creation of all finding aids intended for online access. ${ }^{31}$

\section{Applying EITA Procedures at UM}

The Resolution Agreement with the OCR required the Mansfield Library to make its website accessible and to conduct a monthly accessibility scan. For website accessibility, both the OCR and the DOJ currently use WCAG, Level AA as their minimum standard; ${ }^{32}$ all UM web pages are expected to meet this standard. In its guidance for state and local governments, the DOJ noted, "For most websites, implementing accessibility features is not difficult and will seldom change the layout or appearance of web pages. These techniques also make web pages more usable both by people using older computers and by people using the latest technologies (such as personal digital assistants, handheld computers, or web-enabled cellular phones)." 33 Following the Resolution Agreement, UM migrated all its web pages, including the Archives and Special Collections (A\&SC) site, to a centrally managed content management system. Web page editors and developers at UM attend training sessions to learn about designing for accessibility, including appropriate use of fonts, colors, and navigation features. ${ }^{34}$

The redesign for basic A\&SC web pages, such as lists of resources, services, and procedures, went relatively quickly, as this usually just involved adding descriptive links and section headers. However, A\&SC staff invested significant time in adding alt-text to images in online exhibits created since July 2013 (the date set by the Resolution Agreement for retroactive accessibility actions on web pages). ${ }^{35}$ In the case of exhibit images that include text, such as newspaper clippings, optical character recognition software was used when feasible. As resources become available, or as online exhibits are migrated to new platforms, those created prior to 2013 will be updated to meet accessibility expectations. Because adding headings and alt-text can improve search engine optimization and because the new content management system facilitates use of the 
website with mobile technology, these enhancements should improve general access to A\&SC resources. Accessibility features such as alt-text are also used on the A\&SC Facebook page ${ }^{36}$ and A\&SC staff closed-caption department outreach videos. ${ }^{37}$

Meeting UM's EITA requirements also means that any document a UM employee creates to share with others should be accessible to a person using assistive technology, regardless of whether that document will be posted online. Numerous websites offer information about how to create accessible documents. ${ }^{38}$ As just a very few examples, rather than relying on visual cues such as large font or bold type to indicate sections in a Word document, the styles feature should be used to format the document with a heading structure. Using styles has the added bonus of retaining the structure if the document is converted to PDF or HTML. (If this article is accessible, a screen reader should easily navigate from the title to the section headers Introduction, Legislative Review, Literature Review, etc.) Spreadsheets and other documents with tables should have column and row headers designated using the specific software features for those headers. Rows and columns should not be left blank. Bulleted or numbered lists can be easier than tables for a person using a screen reader to navigate. PowerPoint slides should be created with existing rather than custom templates, fonts should be sans-serif, and mouse clicks should not be required to advance slides. PDFs should incorporate additional document metadata in the properties fields (such as the title and author fields). Any document that has hyperlinks should use descriptive links, and all images should be tagged with alt-text. Using these features takes only seconds or minutes more time than not using them and can vastly improve access by someone using assistive technology.

The university's EITA policy and procedures include this phrase: "The Mansfield Library will implement procedures for ensuring that materials digitized or hosted by the library for research purposes are accessible to individuals with disabilities." ${ }^{39}$ Following the Resolution Agreement, the Mansfield Library established procedures that articulate a difference between noncourse materials and materials designated specifically for classroom and instructional use (such as libguides, e-books, library research databases, and several A\&SC online exhibits). This difference determines when and how the library makes content accessible. Currently, digitized historic collections and the web archives (crawls and captures of UM web pages) are categorized as noninstructional or noncourse materials, meaning they are not identified for specific use within a physical or online classroom at UM. ${ }^{40}$ The library has articulated in its accessibility procedures that making fully accessible all content placed online before 2013, as well as newly scanned historical materials, would constitute an "undue burden" ${ }^{41}$ as defined by Section 508, citing guidelines established by the US Department of Health and Human Services. ${ }^{42}$ Still, the library (including A\&SC) strives to ensure that all content it digitizes and places online is at least minimally accessible. This effort reflects the university's overall mandate, the professional ethics of inclusion and equal access, and an awareness that these materials could be of value for classroom and instructional use.

Efforts to make materials accessible do have resource implications. Some accessibility measures require no changes or only minor changes to workflow. For example, rather 
than saving scanned text as an image file, saving that same scan as a text file and then running the file through optical character recognition software adds only one step and often produces enough recognizable text for users to know whether that document may be valuable to their research. ${ }^{43}$ Rich descriptive metadata (such as author/creator, description, date of original, and source collection) can often be drawn directly from the collection-level archival record. ${ }^{44}$ Some accessibility efforts take longer; each hour of oral history interview takes approximately eight hours to transcribe and edit. However, as with most cases incorporating universal or accessible design, many users benefit. For example, transcripts may be helpful to nonnative speakers, to individuals with cognitive impairments, and to those wishing to quickly keyword search an interview, as well as to individuals with hearing deficits.

UM's Electronic and Information Technology Accessibility procedures also apply to the purchase and procurement of products and services. Most access to content digitized by A\&SC, as well as content from or about A\&SC collections, is provided through vendorhosted services. Guides to archival collections are made available online via Archives West, a service of the Orbis Cascade Alliance. The library uses Montana Memory Project, a hosted instance of OCLC's CONTENTdm, to provide access to digitized maps, photographs, pamphlets, and manuscript materials. Berkeley Electronic Press's Digital Commons serves as the library's institutional repository and provides access to theses and dissertations, oral history audio and transcripts, digitized university publications, and some digitized university records and manuscript collections.

Following the Resolution Agreement, procurement of EIT was centralized and overseen by the university's new Accessible Technology Services (ATS) office. Each vendor the university contracts with for EIT is asked to submit a Voluntary Product Accessibility Template (VPAT), ${ }^{45}$ a tool used to document a product's conformance with Section 508 accessibility standards. The university requires the VPAT even if the technology will be used by only one university employee and is not intended for external or student access. ATS evaluates a product without a VPAT, or with a VPAT that indicates the product is not in conformance. If a product is provisionally approved for use, the vendor is asked to document efforts to improve accessibility features within a period of time. ${ }^{46}$ The United States Access Board, a federal agency promoting equality for people with disabilities, requires that

If products are commercially available that meet some but not all of the standards, the agency must procure the product that best meets the standards. (c) Except as provided by $\$ 1194.3(\mathrm{~b})$, this part applies to electronic and information technology developed, procured, maintained, or used by agencies directly or used by a contractor under a contract with an agency which requires the use of such product, or requires the use, to a significant extent, of such product in the performance of a service or the furnishing of a product. ${ }^{47}$

A recent review of the Archives West interface by ATS highlighted a number of accessibility challenges when attempting to use the site with a screen reader, including the 
lack of clear navigational structure. ${ }^{48}$ CONTENTdm and Digital Commons provided VPATs and are currently approved for use at UM, although a 2015 article by Wendy Walker and Teressa Keenan noted that not every aspect of these products is currently accessible using screen readers. ${ }^{49}$ Very few EIT products are 100 percent accessible, and UM's ATS does approve and reapprove the use of nonaccessible or not fully accessible EIT. Given the federal requirements cited above, however, EIT vendors may wish to proactively incorporate accessibility in design (or redesign) not only to support broader use, but also to position themselves as "the product that best meets the standards."

\section{Conclusion}

This article's goal is to raise awareness of accessibility challenges that users of archives and special collections may face when they interact with their products, resources, and services in an electronic environment. It is also a call on colleagues to encourage those who create products and services for use by archives and other cultural heritage institutions to design their EIT for use by assistive technologies. Of course, the willingness and ability of an archives to adopt practices and acquire products that make its materials more accessible to individuals with disabilities, including those using assistive technologies, will depend on its own mission, goals, and resources. Just as there are resource and access trade-offs between item-level and minimal processing, and situations in which one method may be more appropriate than another, decisions related to electronic and information technology should be made with an awareness of the resource, legal, and ethical implications for access. The Resolution Agreement and UM's EITA policy did not come with additional money to facilitate the library's response, and the Mansfield Library's Archives and Special Collections is far from fully accessible at this time. A well-funded oral history program may decide that every video interview will be fully captioned and posted, along with an accessible transcript, to its own accessible website. Another repository may choose to post its video interviews on YouTube and rely on YouTube's auto captioning for transcription. One repository may post a scanned letter with minimal metadata, and another may extensively edit to ensure a complete and accurate transcription of the original. One repository may need to rely on vendor-provided products, enabling existing features that support use by assistive technology (such as those that allow users to download files onto their own devices for opening with their preferred software), while others will design and support their own accessible interfaces. Happily, many of the tools and services that make content more accessible to individuals with disabilities also benefit other users of archives and special collections.

In the words of Daria D'Arienzo, "Accommodation and access are not disability issuesthey are human issues." ${ }^{50}$ Given the statistics, every repository likely has one or more individuals within its intended audience who has some sort of disability. A professional commitment to diversity includes striving to make content equally available. A professional commitment to access and use means consciously increasing awareness of accessibility issues and working proactively —individually and collectively — to eliminate accessibility barriers for people with disabilities. 


\section{ABOUT THE AUTHOR}

Donna E. McCrea is a tenured professor and head of Archives and Special Collections at the University of Montana-Missoula, where she has worked since 2003. Her daily responsibilities include collection development, reference, course-integrated instruction, outreach, and project and personnel management. Her research interests include mentoring, leadership development, and encouraging the discovery and use of archival collections. She received her MLIS from the University of Wisconsin-Milwaukee in 1999.

\section{NOTES}

1. I wish to thank Lisa Snider and Mark Greene for sharing their knowledge and directing me to sources I had not discovered on my own, and John Fleckner and the anonymous reviewers of an early draft of this article for their valuable comments and suggestions.

2. The University of Washington maintains a web page about lawsuits and resolution agreements related to inaccessible information technology at institutions of higher education. See "Resolution Agreements and Lawsuits," University of Washington, accessed April 19, 2016, http://www .washington.edu/accessibility/requirements/accessibility-cases-and-settlement-agreements/.

3. Office for Civil Rights, OCR Reference No. 10122118. One source for this citation is Office for Civil Rights, Resolution Agreement between the University of Montana and the US Department of Education, Office for Civil Rights, accessed June 20, 2016, http://www2.ed.gov/about/offices/ list/ocr/docs/investigations/more/10122118-b.pdf.

4. Office for Civil Rights, Resolution Agreement. See also, "EITA Policies and Procedures," University of Montana Accessibility, accessed April 19, 2016, http://www.umt.edu/accessibility/implementation/policy/default.php.

5. “Accessibility," University of Montana Accessibility, accessed April 19, 2016, http://www.umt.edu/ accessibility/.

6. Ibid. More recent resolution agreements have used the following language: "Accessible' means a person with a disability is afforded the same opportunity to acquire the same information, engage in the same interactions, and enjoy the same services as a person without a disability in an equally effective and equally integrated manner, with substantially equivalent ease of use. The person with a disability must be able to obtain the information as fully, equally and independently as a person without a disability." Cited in Lucy France and Hannah S. Ross, "Building an Accessible Digital World: The Obligation to Make Electronic Resources Accessible," NACUANote 00120509 preprint (2016): 6.

7. Titles II and III of the Americans with Disabilities Act of 1990 ("Title II"), 42 U.S.C. § 12131 et seq., and its implementing regulation at 28 C.F.R. Part 35.

8. Section 504 of the Rehabilitation Act of 1973, as amended, 29 U.S.C. 794, states that the ADA defines an individual with a disability as a person who has a physical or mental impairment that substantially limits one or more major life activities, a person who has a history or record of such an impairment, or a person who is perceived by others as having such an impairment.

9. “Section 508 Law and Related Laws and Policies," Section 508.gov, accessed April 11, 2016, http:// www.section508.gov/content/learn/laws-and-policies.

10. Office for Civil Rights, Department of Education and Department of Justice, joint "Dear Colleague Letter," June 29, 2010, as cited in Lucy France and Hannah S. Ross, "Disability in the Internet Age," NACUA 55thAnnual Conference Proceedings, accessed June 20, 2016, http://www.cmcgc.com/ media/handouts/350627/8B_Disability\%20Issues\%20in\%20the\%20Internet\%20Age.pdf.

11. Edward L. Myers III, "Disability and Technology," Montana Law Review 65 (2004): 290. 
12. "Nearly 1 in 5 People Have a Disability in the U.S., Census Bureau Reports," United States Census Bureau, accessed April 11, 2016, https://www.census.gov/newsroom/releases/archives/miscellaneous/cb12-134.html.

13. "SAA Core Values Statement and Code of Ethics," Society of American Archivists, accessed April 11, 2016, http://www2.archivists.org/statements/saa-core-values-statement-and-code-of-ethics.

14. "Code of Ethics for Museums," American Alliance of Museums, accessed April 18, 2016, http:// www.aam-us.org/resources/ethics-standards-and-best-practices/code-of-ethics.

15. "Code of Ethics of the American Library Association," American Library Association, accessed April 18, 2016, http://www.ala.org/advocacy/proethics/codeofethics/codeethics.

16. "Special Issue on Services to Patrons with Print Disabilities," Association of Research Libraries, RLI 281 (December 2012): 2

17. Lance J. Fischer, "The Deaf and Archival Research: Some Problems and Solutions," The American Archivist 42 (October 1979): 463, accessed April 11, 2016, http://americanarchivist.org/doi/ pdf/10.17723/aarc.42.4.bt681138560032x2.

18. Brenda Beasley Kepley, "Archives: Accessibility for the Disabled," The American Archivist 46 (Winter 1983): 46, accessed April 11, 2016 http://americanarchivist.org/doi/pdf/10.17723/ aarc.46.1.7275k33t7817w00u.

19. Ibid.

20. Ronald L. Gilardi, "The Archival Setting and People with Disabilities: A Legal Analysis," The American Archivist 56 (Fall 1993): 709-12, accessed April 11, 2016, http://americanarchivist.org/ doi/pdf/10.17723/aarc.56.4.68070hw410848230.

21. Frank H. Serene, Making Archives Accessible for People with Disabilities (Washington, DC: National Archives and Records Administration, 2008), accessed April 16, 2016, http://www.archives.gov/ publications/misc/making-archives-accessible.pdf.

22. "Best Practices for Working with Archives Researchers with Physical Disabilities," Society of American Archivists, accessed April 11, 2016, http://www2 archivists.org/standards/best-practicesfor-working-with-archives-researchers-with-physical-disabilities. The Joint Working Group also created "Best Practices for Working with Archives Employees with Physical Disabilities," accessed April 11, 2016, http://www2.archivists.org/sites/all/files/BestPract-Disabilities_Employees_0.pdf.

23. "Welcome to the Accessibility Working Group," SAA AMRT/RMRT Joint Working Group on Accessibility in Archives and Records Management, accessed June 20, 2016, http://www2.archivists .org/groups/amrtrmrt-working-group-on-accessibility\#.V2hXN6IS7EY.

24. "Web Content Accessibility Guidelines (WCAG Overview),"WC3, accessed April 16, 2016, https:// www.w3.org/WAI/intro/wcag.php. WCAG guidelines are published by the World Wide Web Consortium (W3C), an international community of experts who specify standards for developing web content. See "Web Design and Applications: Accessibility," WC3, accessed April 16, 2016, http://www.w3.org/standards/webdesign/accessibility.

25. Lora Davis, "Providing Virtual Services to All: A Mixed-Method Analysis of the Website Accessibility of Philadelphia Area Consortium of Special Collections Libraries (PACSCL) Member Repositories," The American Archivist 75 (Spring/Summer 2012): 38-41.

26. According to "Guide to Assistive and Accessible Technologies," Disability.gov, "assistive technology (AT) includes any piece of equipment, product or system that is used to "increase, maintain or improve the functional capacities of people with disabilities,"” accessed June 16, 2016. https://www .disability.gov/resource/disability-govs-guide-assistive-technology/. Some examples are wheelchairs, screen readers, eye gaze trackers, building modifications, screen enlargement software, and speech recognition software.

27. Lisa Snider, “Access for All: Making Your Archives' Website Accessible for People with Disabilities," Reference and Access: Innovative Practices for Archives and Special Collections, ed. Kate Theimer (Lanham, MD: Rowman and Littlefield, 2014), 143. Snider's slides for a presentation at SAA's 2011 Accessible Archives Forum are also an excellent source of information: "Accessibility for All Forum: Tips on Website and Document Accessibility," accessed June 20, 2016, http://www .lisasnider.ca/Snider_WebSiteDocAccessibility_SAAChicagoForum2011.pdf. For additional information about making websites accessible, see, for example, chapter 4 of Char Booth, ed., "Web 
Accessibility and Universal Design: A Primer on Standards and Best Practices for Libraries," in Making Libraries Accessible: Adaptive Design and Assistive Technology (Chicago: American Library Association, 2012); chapter 7 of Jane Vincent, Making the Library Accessible for All: A Practical Guide for Librarians (Lanham, MD: Rowan and Littlefield, 2014); and the University of Michigan Accessibility Quick Guide, accessed June 20, 2016, http://webaccess.hr.umich.edu/best/quickguide .html. WebAIM (web accessibility in mind) offers WAVE, a website accessibility tool, accessed June 20, 2016, http://wave.webaim.org/.

28. Kristina L. Southwell and Jacquelyn Slater, "Accessibility of Digital Special Collections Using Screen Readers," Library Hi Tech 30, no. 3 (2012): 464.

29. Ibid., 465.

30. Kristina L. Southwell and Jacquelyn Slater, "An Evaluation of Finding Aid Accessibility for Screen Readers," Information Technology and Libraries 32, no. 3 (2013): 38.

31. Ibid., 44.

32. UM Legal Counsel Lucy France and her Princeton colleague Hannah S. Ross wrote, "It is important to note that the OCR states in its letters to Youngstown State University (November 2014) and the University of Cincinnati (December 2014), however, that its reliance on Section 508, WCAG, and/ or other standards 'does not imply that conformity with such standards is either required or sufficient to comply with the requirements of either Section 504 or Title II.' The OCR may reasonably be trying to lay the groundwork for evolving (and increasing) technology requirements in a world where technological change is omnipresent, by saying: 'Adherence to the WCAG standards today may not be enough tomorrow." France and Ross, "Building an Accessible Digital World, 15.

33. "Accessibility of State and Local Government Websites to People with Disabilities," US Department of Justice, accessed April 18, 2016, http://www.ada.gov/websites2.htm.

34. As noted above, the WC3 is a good source of information about making web content accessible. See, for example, the Web Accessibility Initiative (WAI) web page, which includes a list of evaluation tools, https://www.w3.org/WAI/. See also the WebAIM (web accessibility in mind) resources page, http://webaim.org/resources/. The website Accessibility and Usability at Penn State is also an excellent resource, http://accessibility.psu.edu/. All accessed April 18, 2016.

35. According to the terms of the Resolution Agreement, websites published before July 30, 2013, are considered "legacy." Legacy pages do not need to be redesigned, but must be "made accessible upon request or equivalent access provided."

36. Facebook has recently expanded its accessibility features. See "Accessibility for People with Disabilities," Facebook, accessed April 19, 2016, https://www.facebook.com/help/141636465971794/.

37. In February of 2015, the National Association for the Deaf filed two class action lawsuits against Harvard University and against the Massachusetts Institution of Technology for failing to caption the content they made available online. More information about these cases is available at "The National Association of the Deaf et al. v. Harvard, MIT," Civil Rights Education and Enforcement Center, CREECblog, accessed April 4, 2016, http://creeclaw.org/online-content-lawsuit-harvardmit/.

38. See, for example, WebAIM articles about rich media accessibility, April 18, 2016, http://webaim .org/articles/. See also the documentation provided by individual software creators, such as "Accessibility in Microsoft Products," Microsoft Office, accessed April 18, 2016, https://www.microsoft .com/enable/products/office2010/.

39. "EITA Policies and Procedures."

40. Several A\&SC-produced online exhibits were being used in UM courses.

41. As defined by the United States Access Board, "Undue burden means significant difficulty or expense. In determining whether an action would result in an undue burden, an agency shall consider all agency resources available to the program or component for which the product is being developed, procured, maintained, or used." "Section 508 Standards for Electronic and Information Technology," United States Access Board, accessed June 20, 2016, https://www.access-board.gov/guidelinesand-standards/communications-and-it/about-the-section-508-standards/section-508-standards. (In practice, this would mean not just the resources available to A\&SC but to all of UM.) 
42. "Guidelines for Determining the Suitability of an Accessibility Accommodation," US Department of Health and Human Services, accessed June 20, 2016, http://www.hhs.gov/web/section-508/ accessibility-accomodation/index.html.

43. A\&SC's obligation to respond to a request for additional clean-up work on a document to make it more fully accessible can depend on whether the requester is a UM student and the document is needed for classroom use.

44. See, for example, the metadata provided for the digitized Henry K. Hashatani diary as presented in the Montana Memory Project, accessed April 18, 2016, http://mtmemory.org/cdm/ref/collection/ p16013coll52/id/7.

45. For information about the VPAT, see, for example, "IT Accessibility Handbook," North Carolina State University, accessed December 12, 2016, https://accessibility.oit.ncsu.edu/it-accessibility-atnc-state/developers/accessibility-handbook and “Accessibility," Information Technology Information Council, accessed April 18, 2016, http://www.itic.org/policy/accessibility/. In part because vendor reporting can be inconsistent, some institutions have determined that a VPAT alone is not sufficient and that institutions should independently evaluate products. See, for example, "Procuring Accessible IT," University of Washington, accessed April 18, 2016, http://www.washington.edu/ accessibility/procurement/.

46. As a specific example, a March 2016 request by the Mansfield Library to use DuraSpaces' DuraCloud preservation service was given a one-year conditional approval only, in part because the product's Sync Tool was not accessible to screen readers.

47. United States Access Board, "Section 508 Standards for Electronic and Information Technology," citing as authority: 29 U.S.C. 794d; citing as source: 65 FR 80523, December 21, 2000, accessed December 12, 2016, https://www.access-board.gov/guidelines-and-standards/communicationsand-it/about-the-section-508-standards/section-508-standards.

48. Archives West was reviewed by UM ATS on April 12, 2016, using JAWS for Windows, version 17.0.1806 and IE 11. A summary of results and a screen capture with audio of the review session were provided to the Orbis Cascade Alliance on June 6, 2016.

49. Wendy Walker and Teressa Keenan, "Do You Hear What I See? Assessing Accessibility of Digital Commons and CONTENTdm," Journal of Electronic Resources Librarianship 27, no. 2 (2015).

50. Daria D’Arienzo, "At Heart a Human Issue," remarks at Archival Accessibility for All: An Awareness Forum, Society of American Archivists 2010 Annual Meeting, accessed June 20, 2016, http:// saa.archivists.org/Scripts/4Disapi.dll/4DCGI/store/PDFs/conf/dc2010/Archival-Accessibility_ DArienzo.pdf. 